\title{
Economic Valuation of Private Sector Waste Management Services
}

\author{
Eugene E. Ezebilo (Corresponding author) \\ Swedish University of Agricultural Sciences \\ Southern Swedish Forest Research Centre, Box 49, SE-230 53 Alnarp, Sweden \\ Tel: 46-40-415-197Ｅ-mail: eugene.ezebilo@slu.se
}

Emmanuel D. Animasaun

Malmö University, Department of Public Health, Malmö, Sweden

Received: May 6, 2011

Accepted: June 7, 2011

doi:10.5539/jsd.v4n4p38

\begin{abstract}
This paper reports a study regarding households' willingness to pay for private sector solid waste management services. The data originated from a contingent valuation survey conducted in 224 households in Ilorin in southwest Nigeria and was analysed using tobit and censored least absolute deviations models. The use of a robust and consistent estimator to model zero willingness to pay responses was discussed. The results show that the respondents were willing to pay more than one percent of their household income per year. Their willingness to pay amount was influenced by income, education, activities of sanitary inspectors, house type and occupation. The censored least absolute deviations model outperformed the tobit model. We suggest that government agencies should be actively involved in monitoring activities of private firms regarding provision of waste management services. The findings from this study can help policy-makers in designing a more sustainable waste management strategy in southwest Nigeria, as well as in other developing countries.
\end{abstract}

Keywords: Environmental quality, Local participation, Sustainability, Tobit model, Willingness to pay

\section{Introduction}

Increase in human population and income leads to an increase in demand and production of goods (Varian, 2010; Blanchard, 2009) and consequently more waste are discharged to the environment. If waste is not properly managed it threatens environmental quality and public health (Asase, 2009). For example, harmful substances from improperly disposed waste can contaminate ground water. This often have health implications especially for communities in developing countries where some people drink well water. Although, waste may occur in solid, liquid and gaseous states, however solid waste is the most conspicuous and can easily be noticed by people, thus this study has focused on solid waste management. Waste management services in urban areas in some developing countries are often provided by governments, in the foreseeable future the government may not be able to undertake these services because of dwindling financial resources and reduced allocations to waste management sector. This makes some form of private sector participation desirable. The sector can provide the needed capital for investment in municipal solid waste (MSW) management (i.e. collection and disposal of solid waste) and their involvement can help to increase efficiency. An integrated approach in MSW management (Ahmed and Ali, 2004; Baud and Post, 2001), i.e. involvement of all stakeholders (e.g. government, private sector and residents) can help reduce solid waste problems and promote sustainable waste management in developing countries. In order to sustain private sector participation in MSW management there is a need to provide the sector with incentives (e.g. rewards). For example, introduction of user fees for private MSW services, i.e. urban residents paying for private waste management services. Before introducing user fees it will be interesting to examine whether urban residents would be willing to pay for private sector solid waste management services.

Benefits that people derive from effective and efficient MSW management such as improvement in environmental quality cannot be reflected in normal market prices (Anaman and Jair, 2000) because it has the characteristics of non-market priced good, i.e. non-excludability and non-rivalry (Harris, 2006; Ezebilo, 2011). It is typically estimated by means of non-market valuation methods (Mitchell and Carson, 1989; Loomis, 1993). The contingent valuation method has been the most used non-market valuation method for estimating the economic value of non-market goods (Boman et al., 2008; Ezebilo, 2010; Carson, 2004; Carson et al., 1996). It uses survey questions to elicit people's preferences for non-marketed goods by asking them how much they would be willing to pay for specified improvements or to avoid decrements in them (Mitchell and Carson, 1989). Willingness to pay for non-market goods is often characterised by the presence of many individuals that would not be willing to pay anything at all. In this case ordinary least squares regression estimates will be inconsistent as it fails to account for qualitative differences between zero and positive willingness to pay values (Greene, 2003). This often results in coefficient estimates that are biased toward zero. To deal with this problem the tobit model (Tobin, 1958; Mwebaze et al., 2010; Kimmel and Connelly, 2007; Takehiro, 2008; Ezebilo et al., 2010) 
has been widely used. The tobit estimator (i.e. maximum likelihood estimates) assumes that the error term is homoscedastic and normally distributed. Misspecification of the tobit model leads to inconsistence of the estimates (Robinson, 1982; Hurd, 1979; Nelson, 1981; Goldberger, 1983; Arabmazar and Schmidt, 1981; Yoo et al., 2001). One way of dealing with the problem is to use estimation methods (e.g. semi-parametric) that provide consistent estimates when the error term is non-normal and heteroscedastic (Powell, 1984; 1986; 1994). This study contributes to the existing literatures (Yoo et al., 2000; Huang et al., 1986; Chay and Powell, 2001) regarding the application of semi-parametric method on censored data. Although, urban residents' valuations regarding private sector participation in municipal solid waste (MSW) management can help policy-makers to package waste management that might be more acceptable and cost efficient, there are only few published studies on contingent valuation regarding waste management in developing countries (e.g. Altaf and Deshazo, 1996; Rahji and Oloruntoba, 2009; Murad et al., 2007). The study reported in this paper will help to fill the knowledge 'gap'. The paper has two major aims. The first is to estimate households' willingness to pay for private sector solid waste management services and its determinants to improve environmental quality, as well as promote sustainable waste management in Ilorin in southwest Nigeria. The second aim is to explore the use of consistent and robust estimator when estimating a willingness to pay equation using zero response data.

\section{Materials and methodology}

\subsection{The study area}

Ilorin, the capital of Kwara State in southwest Nigeria has an area of $100 \mathrm{~km}^{2}$ (Kwara State Nigeria, 1997). Like many traditional cities in Nigeria, Ilorin retains the characteristics of traditional town alongside a modern urban centre. The city can be classified into three sub-areas (Aderamo, 2000), i.e. old residential area, new residential area and government reservation area. The old residential area is the indigenous part of Ilorin which is located in the central core area. The new residential area is the post-colonial area located around the core area of the city, while the government reservation area is the high status neighbourhood area. Various types of human activities thrive in Ilorin. The activities include agriculture, trading, transportation and a host of other professionals. The human population of Ilorin was 41,000 in 1952, but was estimated to be 320,000 in 1973 (Olorunfemi, 1982), 477,500 in 1980 (Adedibu, 1985) and 572,178 in 1991. In 2006 the population of Ilorin was 766,000 (National Population Commission, 2006). This suggests that the population of Ilorin is growing rapidly which in turn has the tendency of increasing the amount of solid waste generated in the city. Although, the Ilorin municipal authority have been responsible for waste management in Ilorin, their activities have not been very effective. There are about 129 dump sites in Ilorin (Kwara State Management Council, 2007) some illegal dump sites are still scattered all over the city, mainly at road junctions and interstitial spaces within neighbourhoods. These dump sites often appear, and disappear after the national environmental sanitation days (second and last Saturdays of every month). Like many environmental project in Nigeria (Ezebilo and Mattsson, 2010) the Ilorin residents are rarely involved in planning waste management strategies. The Ilorin city was selected for this study because of the increasing population, urbanization and the increase in waste disposal problems, thus making it a good site for the study of this nature.

\subsection{Survey design and data collection}

The data collection was made by means of hand-delivered questionnaires and interviews that were designed and tested in a town outside the study area. People who had no formal education were interviewed based on the questions in the questionnaire, while people who had formal education were handed a copy of the questionnaire. Pre-test surveys were conducted in April 2009 in thirty randomly selected households in a town outside the study area. The focus groups, personnel of Waste Management Board and the people that were involved during the pre-test surveys helped in the development of questions that were used during the main survey. After the pre-test survey, some questions in the questionnaire (e.g. wordings regarding the valuation question and independent variables) were adjusted to capture concerns raised by survey assistants and respondents. The main survey was conducted during the months of June and July 2009. Six survey assistants were recruited and trained for three days. The assistants were fluent in the local language (Yoruba) of people in the study area and were familiar with the Ilorin city. The Ilorin city was divided into three sub-divisions namely; the old residential area, the new residential area and the government reservation area. Three hundred and thirty households were randomly selected for the survey (110 in each sub-division). If a resident declined the questionnaire/to be interviewed, or there was no an adult individual at the residence contacted, we proceeded to the next residence until the desired sample size of respondents was achieved. The questionnaires/interviews were administered at both weekdays and weekends, as well as during working hours and after working hours, in order to include as many categories of the population as possible during the survey period. Three hundred and twelve questionnaires were handed out to Ilorin residents, only $218(70 \%)$ responded to the questionnaire after two reminders. All people (18) who had no formal education agreed to be interviewed. In total, 236 (72\%) responded to the survey and 224 of the responses were useable for statistical analysis. This reveals that only about $5 \%$ of the responses were not included in the analysis and it should not have a significant impact on the results.

After describing the study (i.e. private provision of waste management services to improve environmental quality) the respondents were asked a series of socio-economic questions (household size, education and income, 
as well as age, occupation, marital status and gender).They were asked about the type of house they live and the travel time from their residence to the nearest dump site. The respondents were asked whether sanitary inspectors do visit their areas. This was followed by the valuation question (see section 2.3) regarding how much they would be willing to pay for private sector solid waste management services.

\subsection{The valuation question}

The hypothetical market scenario was developed to describe increase in frequency regarding collection of solid waste and consequently improvement in environmental quality. This would give Ilorin residents access to a cleaner environment and a lower risk of waste related ailments. The people in the study area are used to monthly payment for services such as electric power. Therefore the monthly payment for solid waste collection services (payment vehicle), was not new to the respondents. Before this study we had doubt about whether the people will respond to the valuation question because Ilorin residents are not used to paying for solid waste management services.

After describing the hypothetical market scenario and the payment vehicle, the respondents were asked whether they were willing to pay anything at all for private sector solid waste management services. If the answer was 'no,' the respondents were asked to give the reason(s). If the answer was 'yes,' the respondents were asked to choose an amount of money from a payment list (50,100,150, 200, 250, and 300 Nigerian Naira) that corresponds to the maximum amount they would be willing to pay monthly for the private sector solid waste management services. The payment list was generated from the suggestions and concerns that were raised by focus groups, some personnel of Waste Management Board and people who participated in pre-test surveys.

\section{Conceptual framework and statistical analysis}

Presently, the management of solid waste in Ilorin is mainly the responsibility of the government. This appears not to be very effective and efficient because it is common to see dump sites in Ilorin littered with waste materials. We assume that if private firms participate in solid waste management in Ilorin it will increase competition, efficiency and consequently improve environmental quality. The respondent $i$ willingness to pay for private sector solid waste management services $W T P$ can be defined using the indirect utility $v$ function:

$$
v\left(P^{0}, Q^{0}, y^{0}\right)=v\left(P^{1}, Q^{1}, y^{1}-W T P\right)
$$

where, $P$ is prices of all the market goods consumed, $Q$ the level of environmental quality $\left(\mathrm{Q}^{1}>\mathrm{Q}^{0}\right), y$ is income. The superscripts 0 represent the initial (status quo) conditions, i.e. municipal solid waste (MSW) management dominated by the government. The superscripts 1 represent the new conditions provided by private sector participation in MSW management. Assuming that the utility function is continuous and quasi-concave, then the respondent's $W T P_{i}$ can be expressed as a function of the respondent's personal characteristics:

$$
W T P_{i}=x_{i} \beta+\varepsilon_{i}
$$

where, $x_{\mathrm{i}}$ is a vector of the respondent's characteristics, $\beta$ is a vector of parameters to be estimated, and $\varepsilon_{i}$ is a random error. In this study the $W T P_{i}$ values were censored at zero, i.e. all reported WTP values are larger or equal to zero. The formulation of the tobit model is:

$$
y_{i}^{*}=x_{i} \beta+\varepsilon_{i}
$$

where, $y_{i}^{*}$ is a latent (unobservable) variable for $W T P_{i}$, and $\varepsilon_{i} \sim N\left(0, \sigma^{2}\right)$, i.e. normally distributed. The observed $y_{i}$ counter part of $y_{i}^{*}$ can be expressed as:

$$
\begin{aligned}
& y_{i}=y_{i}^{*}, \text { if } y_{i}^{*}>0 \\
& y_{i}=0, \text { if } y_{i}^{*} \leq 0
\end{aligned}
$$

The log likelihood function for the tobit model is:

$\log L=\sum_{y_{i}>0}-\frac{1}{2}\left[\log (2 \pi)+\log \sigma^{2}+\frac{\left(y_{i}-x_{i} \beta\right)^{2}}{\sigma^{2}}\right]+\sum_{y_{i}=0} \log \left[1-\Phi\left(\frac{x_{i} \beta}{\sigma^{2}}\right)\right]$

$\Phi$ is the standard normal cumulative distribution function.

\subsection{Statistical analysis}

The tobit model was estimated using the LIMDEP NLOGIT version 4.0.1 statistical package (see Table 2). The variables in the model are described in Table 1 . The existence of heteroscedasticity and non-normality in the error term of the tobit model were tested using the Lagrange multiplier (LM). The null hypothesis of homoscedascity is $\alpha=0$. The LM statistic was calculated as 30.181 . This is asymptotically distributed as chi-squared $X^{2}$ with 10 degrees of freedom. Given that $X_{0.01}^{2}(10)=23.209$, the hypothesis that the model is 
homoscedastic can be rejected at $1 \%$ statistical significant level. The test statistic for normality was computed as 11.162 with 2 degrees of freedom using the LM test. Given that $X_{0.01}^{2}(2)=9.210$, the hypothesis that the error term is normally distributed can be rejected at $1 \%$ statistically significant level. These test results show that the assumptions required to use the tobit model could not be satisfied. As an alternative to the tobit model, the censored least absolute deviations (CLAD) estimator (Powell, 1984) was used. It is consistent and asymptotically normal for a wide class of error distributions with heteroscedasticity of unknown form and a censored dependent variable. This estimator requires less assumption to achieve consistency. For example, the continuity condition is general and does not require homoscedasticity. With this in place the CLAD achieves consistent estimation of parameters of interest (Greene, 2003).

The principles for consistency in the valuation method used in this study means that a point estimate of the individual respondent's maximum willingness to pay (WTP) amount was not determined. Instead, the respondent's true maximum WTP lies in the interval between the respondent's reported WTP and the next higher WTP amount on the payment list (e.g if the respondent reported 50 Nigerian Naira (NGN), then the true WTP will be $75 \mathrm{NGN}$; if s/he reported $300 \mathrm{NGN}$ the true WTP will be $325 \mathrm{NGN}$ ). The respondents' mean willingness to pay for private sector solid waste services $M W T P$ was estimated as:

$M W T P=\frac{1}{n} \sum_{i=1}^{n} \frac{B_{i j}+B_{i k}}{2}$

where, $n$ is the sample size and $B_{i j}$ is the amount reported by the respondent and $B_{i k}$ is the next higher amount on the payment list that was presented to the respondent.

The net present value $N P V$ of a stream of net benefits received over a period of n years was computed as:

$$
N P V\left[B_{1, \ldots .,} B_{n}\right]=\sum_{i=1}^{n} \frac{B_{i}}{(1+r)^{i}}
$$

where $B_{l}$ is the amount of net benefits received the first year, $r$ is the discount rate. In this study we have used the discount rate of $3 \%$.

Multicollinearity (i.e. condition in which two or more independent variables are correlated) is often a problem in this type of study. The variance inflation factor for each variable (see Table 1) was less than 2 and the correlation coefficient between the variables were all less than 0.4 , i.e. multicollinearity was not a serious problem in the estimated model. The variables used in the statistical analysis are presented in Table 1.

\section{Results and discussion}

The average household size of the respondents was 5 persons, while $57 \%$ of the respondents were male and $43 \%$ female (see Table 1). More than $86 \%$ of the respondents were willing to pay for private sector solid waste services. Of these $48.8 \%$ were male and $37.6 \%$ female. The results show that some Ilorin residents have willingness to pay for private sector solid waste services and this suggests that the present solid waste management in Ilorin has not been very effective. About $14 \%$ of the respondents were not willing to pay anything at all for private waste services, most of them were male $(8.24 \%)$ and it was $5.36 \%$ for the female. Women in the study area often have the task of sweeping and collecting solid waste materials in their households therefore if waste management services are ineffective they are more likely to be affected than men. Therefore, women prefer more effective and efficient solid waste services. The most important reason given by the respondents who were not willing to pay anything at all was that they thought that waste management is the responsibility of government. Another important reason was that they raised doubt regarding the capacity of the private sector to manage solid waste services effectively.

The respondents' mean willingness to pay (MWTP) was NGN 389.684/month (US\$ 2.55) this amounts to NGN $4,676 /$ year (US\$ 30.56), i.e. $1.05 \%$ of their household's income per year. Since the human population in Ilorin is 766,000 (National Population Commission, 2006), the number of households there should be 153,200. Aggregating the MWTP amount over the relevant households of 153,200, the total perceived welfare benefit for the private sector solid waste services to Ilorin residents is estimated to be NGN 716,363,200 (US\$ 4,682,112) each year. Assuming a 10 year project life at 3\% discount rate the total net present value of the welfare benefit is NGN 6,112,474,542 (US\$ 39,950,814).

The results of homoscedastic and heteroscedastic tobit models, as well as censored least absolute deviations (CLAD) model estimates for the respondents' willingness to pay for private sector solid waste services are reported in Table 2. The dependent variable was the respondents' willingness to pay for private sector services (WTP). The differences in the coefficient estimates across the various estimators can be used as a sort of specification check (Chay and Powell, 2001). For the coefficients associated with income, education and sanitary 
inspectors, as well as coefficients associated with house type and occupation, the differences between the maximum likelihood (tobit models) and semi-parametric (CLAD) estimates suggest that non-normal errors are an important source of bias in the tobit estimator. It is clear from Table 2 that the maximum likelihood estimates of WTP are extremely biased when compared to the CLAD estimator. When we use the CLAD model as a benchmark, the results show that the heteroscedasticity model actually does better than the homoscedastic model. The results of the heteroscedastic model are a bit similar to those of the homoscedastic model. The signs are all consistent and most of the estimated coefficients are fairly close between the two models. Except for the sanitary inspector and household size variables, the magnitudes of the estimated coefficients for the heteroscedastic are all greater than those obtained from the homoscedastic model. The results presented in Table 2 suggest that the assumption of homoscedastic variance for the sample data used in this analysis may not be very realistic. When compared the CLAD to the homoscedastic and heteroscedastic tobit models, the magnitudes of the estimated coefficients for the CLAD are generally smaller except for the house type, gender, marital status and age variables. The results of the homoscedastic and heteroscedastic tobit models, as well as CLAD model are presented in Table 2.

The coefficient associated with income has a positive and statistically significant effect on the respondents' WTP. This implies that respondents who have more money were more likely to pay more for private solid waste management services. People who have more money often have more capacity to consume foods that are packaged in quick to dispose containers than people who have less money. For example, yoghurt in plastic cans, beef and fish in tin cans, as well as bottled drinks. The more canned food and bottled drinks an individual consumes the more the solid waste materials that will be discharged to the environment is. Hence, people who consume more foods that are packaged in quick to dispose containers are more likely to be affected when solid waste services are ineffective. To avoid such situation these groups of people may be willing to pay more money for an improvement in solid waste services. This suggests that areas where more people who have more money live can be better served by private sector, because they possess more economic power and should value environmental quality more than people who have less money. Areas occupied by people who have less money can be better served by government agencies because the people are less likely to have enough economic power to pay for public goods such as environmental quality. The income variable has the highest statistical significant effect in the homoscedastic model when compared to the heteroscedastic model and the CLAD. This shows that when heteroscedasticity and non-normality is ignored in the tobit model the income effect on WTP will be overestimated.

The coefficient associated with education has a positive and statistically significant effect on the respondents' WTP. This shows that the more the respondents' schooling years the higher the WTP is. A reason may be that more education helps people to comprehend the news about future benefits of effective and efficient solid waste services e.g. improvement in environmental quality and less tendency of environmental pollution related ailments. This indicates that an increase in the awareness of the people regarding proper waste disposal may lead to positive attitude towards environmental cleanliness. The education variable has the least statistical significant effect in the homoscedastic model when compared to the heteroscedastic model and the CLAD. This shows that the effect of education on WTP is underestimated when heteroscedasticity is ignored in the tobit model.

The coefficient associated with sanitary inspectors has a negative and statistically significant effect on the respondents' willingness to pay for private waste management services (WTP). This reveals that the respondents who reside in areas where the activities of sanitary inspectors were strongly noticed were less likely to pay for private waste services. This suggests that the use of sanitary inspectors can help to increase the effectiveness of solid waste management. Increasing the number of sanitary inspectors will attract more costs to the government, thus, it may be better to increase the activities of sanitary inspectors in areas where there is more environmental problems. Since individuals often minimize costs, people who live in areas where the activities of sanitary inspectors are strongly felt may not be willing to pay more money for alternative waste management services because they may not expect more improvement in environmental quality compared to what is obtained at present. If people are satisfied with the present solid waste services they would have less value for alternative waste management services that would cost them more money. It seems that the sanitary inspectors in the study area have contributed to making solid waste management more effective but their activities appear to be more concentrated in some areas. The sanitary inspector variable has higher statistical significant effect in the homoscedastic model when compared to the heteroscedastic model and the CLAD. This shows that the effect of sanitary inspector on WTP is overestimated when heteroscedasticity is ignored in the tobit model.

The coefficient associated with house type has a positive and statistically significant effect on the respondents' willingness to pay for private waste services (WTP). This shows that respondents who live in a single-family dwelling were more likely to pay for private solid waste management services. The occupants of a single-family dwelling house often have more land area than the multi-user dwelling occupants. Some single-family occupants in Nigeria often cultivate horticultural crops to beautiful their premises and some engage in gardening. These activities tend to contribute to generating more solid waste materials (e.g. leaf fall and garden waste). Thus, occupants of the single-family house are more likely to be affected by ineffective solid waste management 
services than multi-user dwelling occupants. For the case of multi-user dwelling the occupants are less likely to have enough incentives to pay for an improvement in solid waste services as they are aware that they can free-ride, i.e. enjoy the benefits free of charge or pay less money. Hence, respondents who live in single-family house were more willing to pay for private waste services. The house type variable has least statistical significant effect in the heteroscedastic model, while the effects in the homoscedastic and CLAD models were similar. This reveals that the effect of house type on WTP is overestimated when heteroscedasticity is ignored in the tobit model.

The coefficient associated with occupation has a negative and statistically significant effect on the respondents' WTP. This suggests that respondents who engaged in formal employment (i.e. jobs that require formal training) such as teaching, nursing and human resource managers were less likely to pay for private solid waste services. A reason may be that it is often employers who have the responsibility to see to the cleanliness of the work environment in their organisation to avoid being penalised by waste management board. Hence, people who engage in formal employment have less incentive to pay for private waste services as opposed to people who are engaged in informal employment such as farming and trading. The occupation variable has higher statistical significant effect in the heteroscedastic model compared to the homoscedastic model. Its effect on the CLAD was not significant. This shows that the effect of occupation on WTP is overestimated when non-normality of the error term is ignored in the tobit model.

The coefficients associated with time taken to travel to the nearest dump site, gender, marital status, age and household size were not statistically significant. However, it should be noted that the coefficient associated with household size has similar signs (negative) for the homoscedastic and heteroscedastic models but positive for the CLAD. This shows that if non-normality of error term is ignored it can lead to a misleading results that may have negative policy implications.

\section{Concluding remarks}

The study reported in this paper has been conducted in a rapidly growing city in a developing country where solid waste management has been a major cause of concern. Although, various agencies have been established to manage municipal solid waste in Ilorin, southwest Nigeria they have not been very successful. In order to gear municipal solid waste management toward sustainability and efficiency we have explored the involvement of private sector. To this end the study has focused on the value that urban residents held regarding private sector solid waste management services. We have used contingent valuation method to elicit the value that people held for the private sector services and this often generate some zero willingness to pay responses. To deal with this problem we have explored the use of a consistent and robust estimator to model the data. The results show that most of the respondents were willing to pay for the private solid waste management services. The effect of different variables on willingness to pay for the services was estimated with tobit and censored least absolute deviations (CLAD) models. The results from the statistical analysis show that respondents who have more money, education and live in a single-dwelling house were more willing to pay for the services, while those who live in areas where the activities of sanitary inspectors were strongly felt and engaged in formal employment were less willing to pay for the services. It also reveals that the tobit model is vulnerable to the existence of heteroscedasticity and non-normal error. The results show that the CLAD estimator is robust under these conditions and can deal with zero response data. In the application reported here, the CLAD outperformed the tobit models, reducing the implicit restrictions involved in the tobit model. Regarding our application, suffice is to say that the CLAD is a practical and theoretically promising way of modelling zero willingness to pay data. Although, private participation in municipal solid waste management is a promising way to increase efficiency the economic behaviour which governs private sector provision of solid waste services may not yield socially optimal outcomes because of the free-rider that is inherent in it. To achieve optimal social outcomes, the intervention of government is required. Private sector should be encouraged to take over only some aspects of solid waste management. The needs of people regarding solid waste management services may differ between income earner categories, housing types and areas. Thus, it is important to consider this variation when designing a sustainable solid waste management strategy.

\section{References}

Adedibu, A.A. (1985). A comparative analysis of solid waste composition and generation in two cities of a developing nation. The Environmentalist 5(2), 123-127.

Aderamo, A.J. (2000). Spatial pattern of intra-urban trips in Ilorin, Geo-studies, 1:47-57.

Arabmazar, A. \& Schmidt, P. (1981). "Further Evidence on the Robustness of the Tobit Estimator to Heteroskedasticity." Journal of Econometrics, 17(2): 253-258.

Ahmed, S.A. \& Ali, M. (2004). Partnerships for waste management in developing countries: linking theories to realities. Habitat International, 28(3), 467-479.

Altaf, M.A. \& Deshazo, J.R. (1996). Household Demand for Improved Solid Waste Management: A case study of Gujranwala, Pakistan. World Development, 24(5) 857-868. 
Anaman, K. \& Jair, R.M. (2000). Contingent valuation of solid waste collection services for rural households in Brunei Darussalam. The Singapore Economic Review, 45(2), 223-240.

Asase, M.,Yanful, E.K., Mensah, M., Stanford, J. \& Amponsah S. (2009). Comparison of municipal solid waste management systems in Canada and Ghana: a case study of the cities of London, Ontario, and Kumasi, Ghana. Waste Management 29 (10), 2779-2786.

Baud, I. \& Post J. (2001). New partnerships in urban solid waste management and their contribution to sustainable development: experiences in Accra and Chennai. In I. Baud, and J. Post (Eds.), Re-aligning government, civil society and market: new challenges in urban and regional development, essays in honour of G. A. de Bouijne. University of Amsterdam Press, Amsterdam.

Blanchard, O. (2009). Macroeconomics. Pearson Education, Inc., Boston.

Boman, M., Norman, J., Kindstrand, C. \& Mattsson L. (2008). On the budget for national environmental objectives and willingness to pay for protection of forest land Canadian Journal of Forest Research 38: No 1.

Boyle, K. \& Bishop, R. (1987). Valuing wildlife in benefit-cost analyses: a case study involving endangered species. Water Resources, 23: 943-950.

Carson, R. (2004). Contingent valuation: A comprehensive bibliography and history. Cheltenham, UK and Northampton, MA: Edward Elgar.

Carson, R., Flores, N., Martin, K. \& Wright, J. (1996). Contingent valuation and revealed preference methodologies: comparing the estimates for quasi-public goods. Land Economics, 72: 80-99.

Chay, K.Y. \& Powell, J.L. (2001). Semiparametric Censored Regression Models. Journal of Economic Perspectives, 15 (4): 29-42.

Ezebilo, E.E. (2011). Local participation in forest and biodiversity conservation in a Nigerian Rain forest. International Journal of Sustainable Development and World Ecology, 18(1):42-47.

Ezebilo, E.E. (2010). Conservation of a leafy vegetable important for communities in the Nigerian rainforest. Forest Ecology and Management, 259, 1660-1665.

Ezebilo, E.E., Mattsson, L. \& Afolami, C. A. (2010). Economic value of ecotourism to local communities in the Nigerian rainforest zone... Journal of Sustainable Development, 3 (1), 51-60.

Ezebilo, E.E. \& Mattsson, L. (2010). Socio-economic benefits of protected areas as perceived by Local people around Cross River National Park, Nigeria. Forest Policy and Economics, 12, 189-193.

Goldberger, A.S. (1983). “Abnormal Selection Bias," in Studies in Econometrics, Time Series, and Multivariate Statistics. S. Karlin et al., (eds.). New York: Academic Press, pp. 67-84.

Greene, W.H. (2003). Econometric Analysis, $5^{\text {th }}$ edition, Prentice Hall, New Jersey.

Harris, J.M. (2006). Environmental and Natural Resource Economics: A contemporary approach. Houghton Mifflin Company, Boston, USA.

Huang, C.L., Raunikar, R. \& Tyan, H.L. (1986). Heteroscedasticity in Broiler Meat Expenditure Pattern Estimation. Western Journal of Agricultural Economics, 11(2): 195-203.

Hurd, M. (1979). "Estimation in Truncated Samples when there is Heteroscedasticity." Journal of Econometrics, $11,247-258$.

Kimmel, J. \& Connelly, R. (2007). Mothers' Time Choices: Caregiving, Leisure, Home Production, and Paid Work, Journal of Human Resources, Vol. 42, No. 3, 643-681.

Kwara State of Nigeria. (1997). Kwara State Diary, Government Press, Ilorin Nigeria. National Population Commission. 2006. Final Results, Kwara State.

Kwara State Waste Management Council. (2007). $2^{\text {nd }}$ phase of Green/Clean - Campaign Booklet. Kwara State Government, Nigeria.

Loomis,J.B. (1993). Integrated public lands management: Principles and applications to national forests, parks, wildlife refuges and BLM lands. New York: Columbia University press.

Mitchell, R.C. \& Carson, R.T. (1989). Using surveys to value public goods: the contingent valuation method. Resources for the future, Washington D.C.

Murad, M.W., Raquib, M.A \& Siwar, C. (2007). Willingness of the poor to pay for improved access to solid waste collection and disposal services. The Journal of Environment and Development, 16(1): 84-101.

Mwebaze, P., MacLeod, A., Tomlinson, D., Barois, H. \& Rijpma, J. (2010). Economic valuation of the influence of invasive alien species on the economy of the Seychelles Islands. Ecological Economics, 69: 2614-2623.

National Population Commission (2006). Final Results, Kwara State. Nelson, F.D. (1981). "A Test for Misspecification in the Censored Normal Model.” Ecconometrica, 49, 1317-13129. 
Olorunfemi, J.F. (1982). Application of aerial photography to population estimation in Nigeria. Geojournal 6(3): 225-30.

Powell, J.L. (1984). Least absolute deviations for censored regression model. Journal of Econometrics, 25, 303-325.

Powell, J.L. (1986). Symmetrically trimmed least squares estimation for tobit models. Econometrica 54, $1435-14460$.

Powell, J.L. (1994). "Estimation of Semiparametric Models," in Handbook of Econometrics, Volume IV. Robert F. Engle and Daniel L. McFadden (eds.). Amsterdam: North Holland, pp. 2443-521.

Rahji, M.A.Y. \& Oloruntoba, E.O. (2009). Determinants of households' willingness to pay for private solid waste management in Ibadan, Nigeria. Waste Management and Research, 27: 961-965.

Robinson, P.M. (1982). On the asymptotic properties of estimators of models containing limited dependent variables. Econometrica, 50, 27-41.

Takehiro, U. (2008). Estimating the effect of unit-based pricing in the presence of sample selection selection bias under Japanese Recycling Law. Ecological Economics, 66: 282-288.

Tobin, J. (1958). Estimation of relationships for limited dependent variables. Econometrica, 26, 24-36.

Varian, H.R. (2010). Intermediate Microeconomics: A Modern Approach. W.W. Norton and Company, New York.

Yoo, S-H., Kim, T-Y \& Lee, J-K. (2001). Modeling zero response data from willingness to pay surveys: A semi-parametric estimation. Economics Letters, 71, 191-196.

Yoo, S-H., Kwak, S-J. \& Kim, T-Y. (2000). Dealing with zero response data from contingent valuation surveys: application of least absolute deviations estimator. Applied Economics Letters, 7, 181-184.

Table 1. Descriptive statistics of respondents' characteristics

\begin{tabular}{|c|c|c|c|}
\hline Variable & Description & Mean & $\%$ \\
\hline WTP & $\begin{array}{l}\text { Willingness to pay for private sector municipal solid waste } \\
\text { services (NGN per household per month) }\end{array}$ & 389.684 & NA \\
\hline INCOME & Household income per year (NGN) & $443,670.000$ & NA \\
\hline TIME & $\begin{array}{l}\text { Travel time from respondent's home to nearest } \\
\text { dumpsite (minutes) }\end{array}$ & 6.540 & NA \\
\hline EDU & $\begin{array}{l}\text { Number of years that the respondent had } \\
\text { formal education }\end{array}$ & 14.700 & NA \\
\hline INSP & $\begin{array}{l}\text { Activities of sanitary inspectors are often noticed in } \\
\text { my area: yes }=1\end{array}$ & NA & 16.5 \\
\hline \multirow{4}{*}{ HOUSE } & no $=0$ & NA & 83.5 \\
\hline & The type of house the respondent lives : & & \\
\hline & Single-family dwelling $=1$ & NA & 43 \\
\hline & Multi-user dwelling $=0$ & NA & 57 \\
\hline \multirow[t]{2}{*}{ GEND } & The gender of the respondent: male $=1$ & NA & 57 \\
\hline & female $=0$ & NA & 43 \\
\hline \multirow[t]{2}{*}{ OCCU } & The respondent's occupation: formal employment $=1$ & NA & 43 \\
\hline & non-formal $=0$ & NA & 57 \\
\hline \multirow[t]{2}{*}{ MARIT } & Respondent's marital status: married $=1$ & NA & 57 \\
\hline & single $=0$ & NA & 43 \\
\hline $\mathrm{AGE}$ & Respondent's age (years) & 37.6 & NA \\
\hline H SIZE & The household size of the respondent (number of person) & 5.0 & NA \\
\hline
\end{tabular}

NGN is the Nigerian Naira (US\$1 = NGN 153); NA is not applicable 
Table 2. Determinants of willingness to pay for private solid waste services

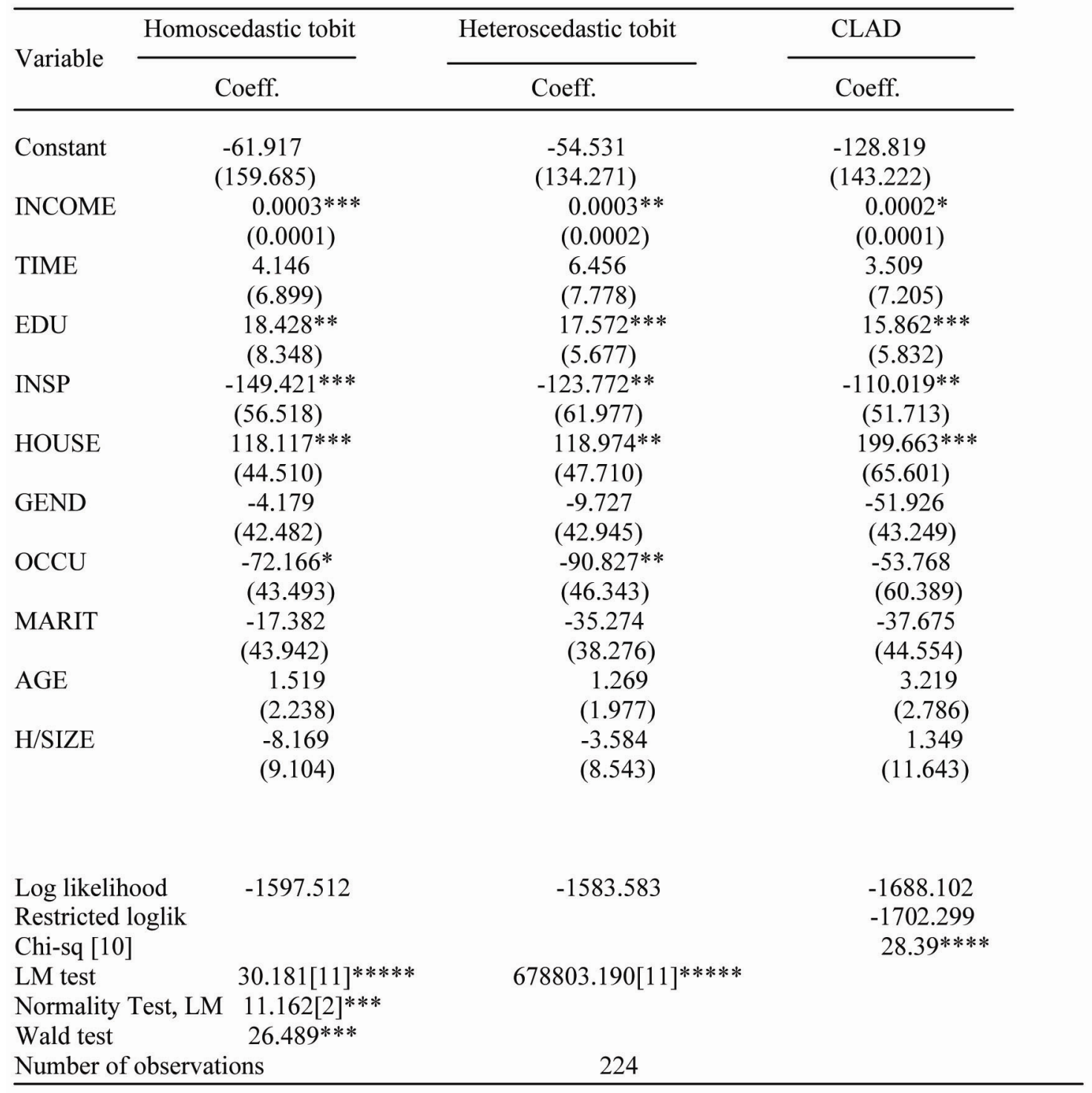

$*, * *, * * *, * * * *$ represent $0.10,0.05,0.01$ and $<0.001$ levels of statistical significance respectively. Standard error is in parenthesis. The CLAD was estimated by the use of the bootstrap method with 5000 replications. 